\title{
Structural Studies of Hydrostatically Extruded Polypropylene
}

\author{
Yoji MAEDA, Kazuo NAKAYAmA, and Hisaaki KaneTSUnA \\ Research Institute for Polymers and Textiles, \\ 1-1-4 Yatabe-Higashi, Tsukuba, Ibaraki 305, Japan.
}

(Received November 13, 1981)

\begin{abstract}
A study was made on the X-ray long period and melting behavior of isotactic polypropylene extrudates with smooth surfaces. The extrusion was effected hydrostatically in the range of extrusion ratio $R_{\mathrm{e}}$ from 2.0 to 6.5 at temperatures of $90-150^{\circ} \mathrm{C}$. It was found that the long period of the extrudates increased with increasing temperature and also at higher extrusion ratios. The crystalline and amorphous layer thicknesses of the products extruded with $R_{\mathrm{e}}=5.2$ and 6.5 at $150^{\circ} \mathrm{C}$ were studied by nitric acid etching followed by a GPC measurement. We found that the extrudate for $R_{\mathrm{e}}=6.5$ had a larger average crystal thickness with narrower crystal size distribution than the extrudate for $R_{\mathrm{e}}=5.2$, but the ratio in thickness of amorphous to crystalline layers was almost the same for the two extrudates. Thickening of crystalline and amorphous layers at high extrusion ratios suggest that heat is generated in the sample near the die during hydrostatic extrusion and influences strongly the fine-structure of the extrudates at high extrusion ratio and high temperature.

KEY WORDS Polypropylene / Hydrostatic Extrusion / X-Ray Long Period / Nitric Acid Etching / Gel-Permeation Chromatography / Average Crystallite Thickness /
\end{abstract}

It is now well established that hydrostatic extrusion causes considerable change in the optical and mechanical properties of polymers. The transparency often increases with extrusion ratio. The strength and stiffness of polymers increase significantly in some cases. Hydrostatic extrusion is essentially a process in which a billet of material is allowed to pass through a die by hydrostatic pressure. One of the advantages of hydrostatic extrusion in polymer processing is that both structure and mechanical properties of polymers can be modified by the deformation process. $^{1-3}$ The amount of deformation, i.e., the extent of polymer chain orientation, can be controlled in the hydrostatic extrusion process, thereby making possible the controll of the mechanical properties of the finished products.

We also investigated the solid-state extrusion of a variety of crystalline polymers such as high density polyethylene, ${ }^{4}$ ultra-high molecular weight polyethylene, ${ }^{5}$ polypropylene, ${ }^{6}$ nylon $12,{ }^{7}$ polyacetal, ${ }^{8}$ and poly(vinylidene fluoride). ${ }^{9}$ In a previous paper, ${ }^{6}$ we reported the relationship among the variables in- volved in the extrusion process of isotactic polypropylene, such as extrusion ratio, extrusion temperature, and extrusion pressure. The effect of temperature and extrusion ratio on the orientation of crystals and mechanical properties of the products were investigated. The extrudates with smooth surfaces were obtained in the extrusion ratio $R_{\mathrm{e}}$ from 2.4 to 6.5 at temperatures of 90 $150^{\circ} \mathrm{C}$. The products at high extrusion ratios were generally transparent. The wide-angle X-ray diffraction patterns of the products changed from a Debye-Sherrer ring to a highly oriented fiber structure with increasing $R_{\mathrm{e}}$. The birefringence also increased monotonously with $R_{\mathrm{e}}$ at each temperature and the product extruded at $110^{\circ} \mathrm{C}$ showed a maximum birefringence. The degree of orientation for both the crystalline and amorphous regions in the extrusion direction, i.e., the $c$-axis orientation, increased with extrusion ratio. Hydrostatic extrusion of isotactic polypropylene at high extrusion ratio changed the sample from microspherulitic crystalline lamellae to highly oriented fiber structure through a complex deformation process involving 
the destruction of spherulitic crystals, rotation and sliding of microcrystals, and rearrangement of microfibrils. However, only a few studies have been reported on the fine structure of extrudates of isotactic polypropylene.

The procedure for degrading polyethylene with fuming nitric acid followed by measuring molecular weight distribution by gel-permeation chromatography has been found useful in understanding the molecular structure of a variety of folded- and extended-chain crystals of polyethylene. In this study, the same procedure has been applied to the extrudates of isotactic polypropylene and an estimation was made of the fine structure of the products extruded hydrostatically at $150^{\circ} \mathrm{C}$ with $R_{\mathrm{e}}=5.2$ and 6.5 .

\section{EXPERIMENTAL}

\section{Materials}

The polypropylene (PP) resin used in the present study was a commercial rod of isotactic polypropylene, Ubepolypro J105G, supplied by Ube Industries, Ltd. The weight-average molecular weight and the weight- to number-average molecular weight ratio, determined by gel-permeation chromatography, were $4.2 \times 10^{5}$ and 6.1 , respectively. The melt index and the heptane-insoluble part were 5 and $95 \%$, respectively.

The apparatus used in this study and the details of the processes of hydrostatic extrusion are given elsewhere. ${ }^{4}$ Extrusion was conducted after putting the billet into the extrusion device, and heating it for about $30 \mathrm{~min}$ at a predetermined temperature. The extrusion temperature ranged from 90 to $150^{\circ} \mathrm{C}$. The extrusion rates were held at $50-100 \mathrm{~mm}$ $\mathrm{min}^{-1}$. The dies had a throat of $8 \mathrm{~mm}$ diameter and $10 \mathrm{~mm}$ length. The diameters of the original billets were $12.2-20.4 \mathrm{~mm}$. The crystal form of all the extrudates was monoclinic modification. The extrusion ratio $R_{\mathrm{e}}$ is defined as the cross-sectional area of the original billet, $\pi R^{2}$, relative to the exit, $\pi r^{2}$, of the die, i.e., $R_{\mathrm{e}}=(R / r)^{2}$. But deformation ratios in extruded samples are usually smaller than $R_{\mathrm{e}}$, since the PP extrudates show 'spring back' or die swelling of about $2-8 \%$.

Two PP extrudates having an extremely high and an ordinary X-ray long period were taken in the present study. Sample (i) was obtained with the highest extrusion ratio of $R_{\mathrm{e}}=6.5$ and sample (ii) was obtained with $R_{\mathrm{e}}=5.2$, both extruded hydrostatically at $150^{\circ} \mathrm{C}$.

\section{Methods of Investigation}

Melting points and heats of fusion were measured on a Perkin-Elmer DSC-II differential scanning calorimeter at various heating rates between 1.25 and $80^{\circ} \mathrm{C} \mathrm{min}{ }^{-1}$. Peak temperature after being corrected for thermal lag was defined as melting point of each endothermic curve. Calibration of the DSC-II was carried out using an indium standard.

Small-angle X-ray scattering (SAXS) patterns were obtained on a Rigaku-Denki diffractometer Rotaunit RU-200 using both vacuum camera and scintillation counter techniques. Ni-filtered $\mathrm{Cu}-\mathrm{K} \alpha$ radiation $(40 \mathrm{kV}, 80 \mathrm{~mA})$ and pinhole collimators, $0.3 \mathrm{~mm}$ and $0.2 \mathrm{~mm}$ in diameter, were used. The specimen-to-film distance was $300 \mathrm{~mm}$.

Densities were measured by the flotation method using a density-gradient formed by toluene and chlorobenzene at $25^{\circ} \mathrm{C}$. The degree of crystallinity was determined with Fallow's density values ${ }^{10}$ for PP: for an ideal crystal, $0.936 \mathrm{~g} \mathrm{~cm}^{-3}$, and for a completely amorphous polymer, $0.870 \mathrm{~g} \mathrm{~cm}^{-3}$.

\section{Nitric Acid Etching}

Details of the nitric acid etching are given in a previous publication. ${ }^{11}$ In this case, the etching of the PP extrudates was carried out in a sealed flask at $70^{\circ} \mathrm{C}$ using a large excess of Analar-grade fuming nitric acid ( $c a .94 \%$ concn, $\left.1.50 \mathrm{~g} \mathrm{~cm}^{-3}\right)$. After a certain period of etching, the samples were taken out and washed in distilled water for $12 \mathrm{~h}$ and then extracted with acetone in a soxhlet apparatus for $6 \mathrm{~h}$. They were finally dried in vacuo at $40^{\circ} \mathrm{C}$ for $12 \mathrm{~h}$.

\section{Gel-Permeation Chromatography}

Average molecular weights and molecular weight distributions of the degraded products were determined with a Waters GPC Model 200, using $o$ dichlorobenzene at $135^{\circ} \mathrm{C}$ as the solvent. A column set with upper porosity ratings of $10^{6}, 10^{5}, 10^{4}, 10^{3}$, and $500 \AA$ was used. Molecular weight calibration for polypropylene was performed with standard polypropylene fractions supplied by the National Physical Laboratory (United Kingdom). The flow rate was about $1 \mathrm{ml} \mathrm{min}^{-1}$ and the injection time was $2 \mathrm{~min}$. The polymer concentration in the injected solution was about $0.2 \%(\mathrm{w} / \mathrm{v})$. The following 
linear equation was obtained by the least-squares regression,

$$
\log M_{\mathrm{pp}}=-0.2829 \times V+12.5417
$$

where $M_{\mathrm{pp}}$ is the weight-average molecular weight of an NPL standard polypropylene fraction, and $V$ is the elution volume at the peak of a GPC curve.

It is well known that etched polar molecules remain in the GPC column longer than the corresponding non-degraded chains, but the retention decreases with increasing molecular weight. ${ }^{12}$ The peak width and peak elution volume become negligible with increasing molecular weight above about 2,000 for polyethylene. ${ }^{13}$ In this study, the effect of molecular weight spread due to polar endgroups on the GPC curves was neglected.

\section{RESULTS}

\section{Melting Behavior}

Figure 1 shows the DSC melting curves of the PP products extruded with four extrusion ratios at $150^{\circ} \mathrm{C}$. Melting behavior of the samples extruded at $110^{\circ} \mathrm{C}$ and $130^{\circ} \mathrm{C}$ followed curves similar to those in Figure 1, but the melting patterns became less distinct on lowering the extrusion temperature. The melting curves of the samples extruded at $90^{\circ} \mathrm{C}$ showed only one broad peak, indicating that the

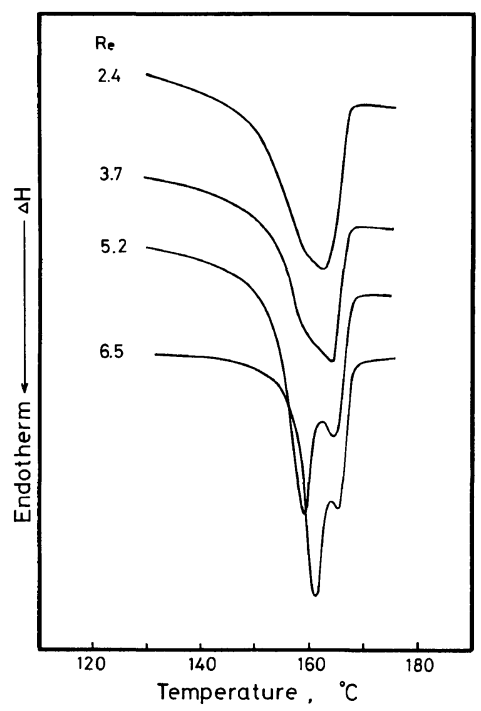

Figure 1. DSC curves of hydrostatically-extruded polypropylenes prepared with the extrusion ratios $R_{\mathrm{e}}$ of $2.4,3.7,5.2$, and 6.5 at $150^{\circ} \mathrm{C}$. overall reorganization of the original structure occurred during the heating process. As shown in Figure 1, the melting peak on the lower temperature side increases with increasing extrusion ratio and shifts to higher temperature. Figure 2 shows the dependence of the melting pattern on the heating rate for the product extruded with $R_{\mathrm{e}}=6.5$ at

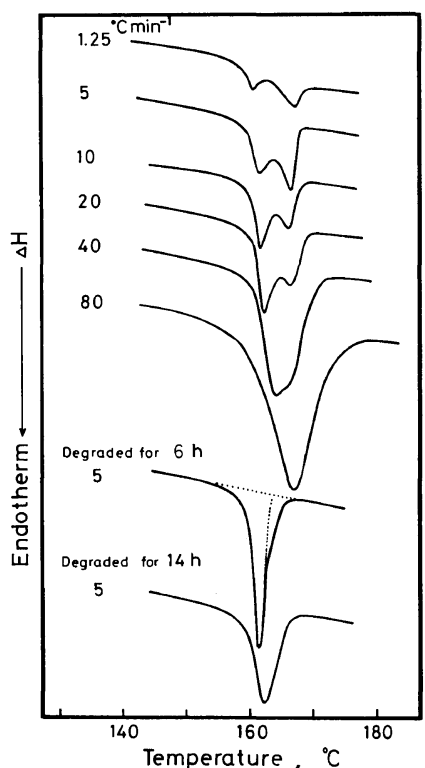

Figure 2. Heating rate dependence of melting pattern for the product extruded with $R_{\mathrm{e}}=6.5$ at $150^{\circ} \mathrm{C}$ and the DSC curves of the same products degraded with fuming nitric acid.

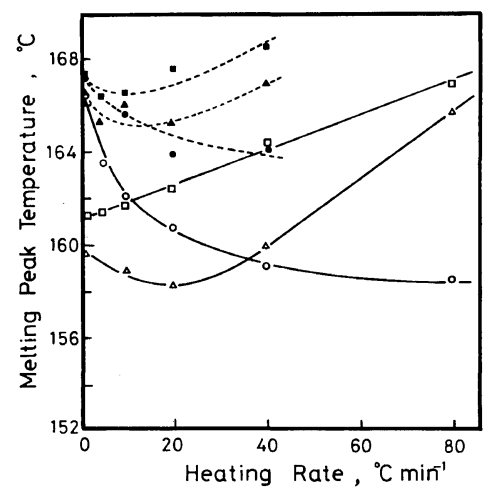

Figure 3. Heating rate dependence of melting peak temperature for the original billet $(O)$ and the two products extruded at $150^{\circ} \mathrm{C}$ with $R_{\mathrm{e}}=5.2(\triangle)$ and 6.5 ( $\square)$. Filled symbols show the heating rate dependence of melting point of the crystal formed during heating process. 
$150^{\circ} \mathrm{C}$. The melting peak on the higher temperature side decreased with increasing heating rate and disappeared at $80^{\circ} \mathrm{C} \mathrm{min}{ }^{-1}$. The melting pattern at

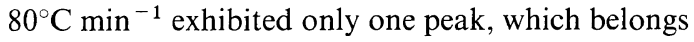
to the peak on the lower temperature side. This behavior suggests that the melting peak on the higher temperature side may be attributed to the fusion of crystals reorganized during the heating. This was confirmed by the melting curves of the PP extrudates degraded with fuming nitric acid as shown in Figure 2. From this figure, it is clearly seen that the melting peak on the higher temperature side is depressed significantly by nitric acid etching for $6 \mathrm{~h}$ and then disappears completely by etching for $14 \mathrm{~h}$. Since acid etching breaks up the chain molecules in the amorphous region between the crystallites and the folds at the crystallite surfaces, reorganization to stabler crystals is thus necessarily inhibited. Accordingly, the melting peak on the lower temperature side can be attributed to the fusion of the original structure formed by hydrostatic extrusion.

Figure 3 shows the relation between melting peak temperature and heating rate for the original billet and the two extrudates. For the original billet, a significant effect of reorganization is observed. The temperatures at both lower and higher melting peaks increase remarkably with decreasing heating rate. The "equilibrium" melting point for the sample was estimated to be $158^{\circ} \mathrm{C}$ from the DSC curve at $80^{\circ} \mathrm{C} \mathrm{min}^{-1}$, and is considered equal to the true melting point of the structure of the starting material. On the other hand, in the case of extrudate with $R_{\mathrm{e}}=6.5$, the temperature at the lower peak decreases monotonously with decreasing heating rate and the "equilibrium" melting point was estimated to be about $161^{\circ} \mathrm{C}$ by extrapolation to the ordinate. A slight effect of reorganization was observed at lower heating rates for the extrudate with $R_{\mathrm{e}}=5.2$. Heat of fusion, $\Delta \mathrm{H}$, for each sample was determined from both the DSC curves at $80^{\circ} \mathrm{C}$ $\min ^{-1}$ and that for the degraded sample. The $\Delta \mathrm{H}$ value for the billet was about $20.0 \mathrm{cal} \mathrm{g}^{-1}$, while the $\Delta \mathrm{H}$ values for both extrudates were about $24.0 \mathrm{cal}$ $\mathrm{g}^{-1}$ each.

\section{$X$-ray Long Period}

Figure 4 shows the typical SAXS patterns of the original billet and the two samples extruded with $R_{\mathrm{e}}=5.2$ and 6.5 at $150^{\circ} \mathrm{C}$. In this figure, the SAXS patterns for both extrudates show two-intensity maxima in the meridian, while the pattern of the billet shows a ring with an isotropic intensity distribution.

The axial long period, indicative of a periodic structure in the hydrostatically extruded specimens, was calculated from SAXS meridional maxima. Figure 5 shows the dependence of this quantity on the extrusion ratio for the PP products extruded at $90,110,130$, and $150^{\circ} \mathrm{C}$. Here, it should be noted that the original billet was easily annealed at higher temperatures before extrusion, and the long period increased with extrusion temperature. At extrusion ratios lower than 4.0 , the long period of any extrudate was smaller than that of the billet annealed at each temperature. This indicates that isotactic PP resin becomes more susceptible to plastic deformation through crystalline orientation with rise in temperature. The mechanical deformation of micro-

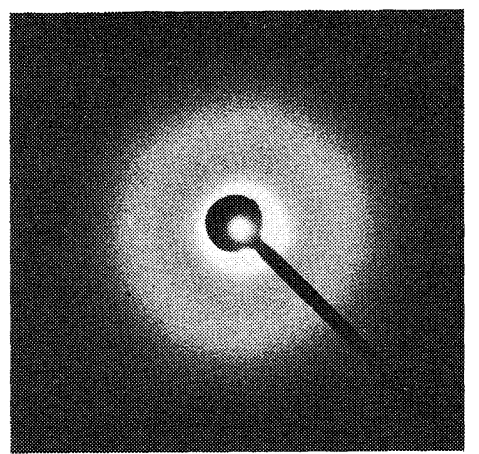

Original

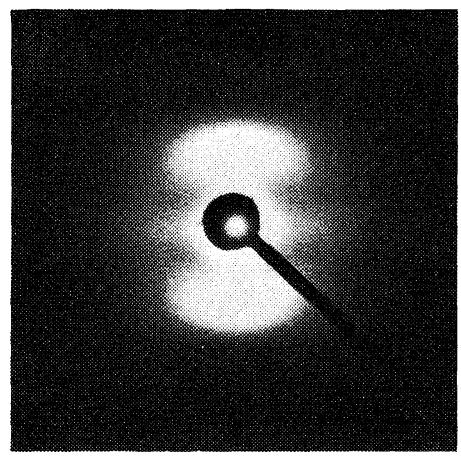

$R_{\mathrm{e}}=5.2$

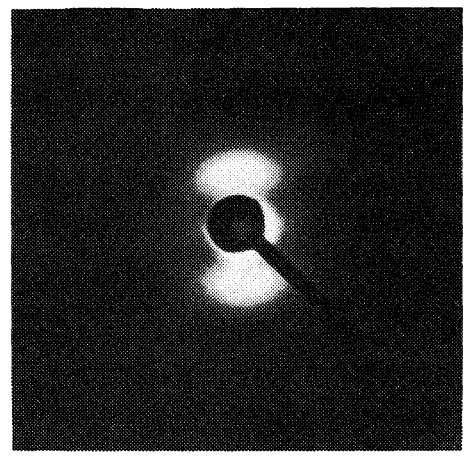

$R_{\mathrm{e}}=6.5$

Figure 4. SAXS patterns of the original billet and the two products extruded with $R_{\mathrm{e}}=5.2$ and 6.5 at $150^{\circ} \mathrm{C}$. 


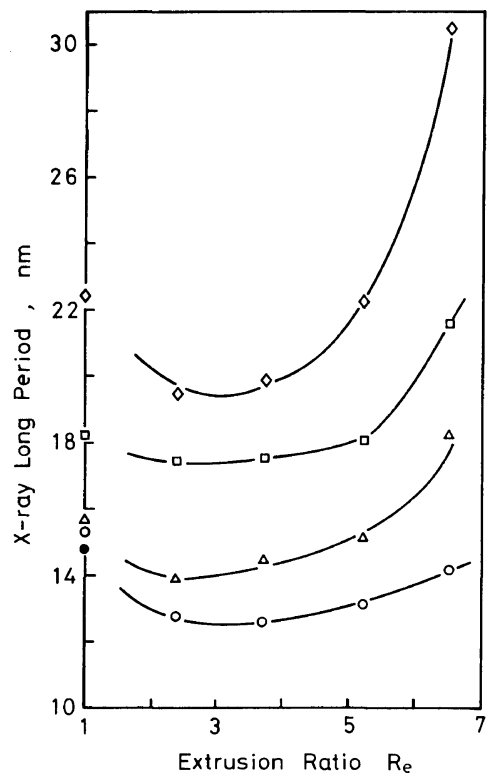

Figure 5. Dependence of X-ray long period on deformation ratio for the $\mathrm{PP}$ products extruded at $90^{\circ} \mathrm{C}(\mathrm{O})$, $110^{\circ} \mathrm{C}(\triangle), 130^{\circ} \mathrm{C}(\square)$, and $150^{\circ} \mathrm{C}(\diamond)$.

spherulitic crystals such as destruction, rotation, and sliding of the crystalline lamellae is prominent in the case of extrusion ratios lower than 4.0. On the other hand, the long period increased significantly at extrusion ratios above about 5.0 and the increase was larger at higher temperatures. The long period of the product extruded at $150^{\circ} \mathrm{C}$ was much larger than that of the billet.

\section{Nitric Acid Etching}

Nitric acid etching and GPC measurement are useful for understanding the molecular structure of polypropylene crystal. ${ }^{14}$ Figure 6 shows the degradation time dependence of density for the original billet and the two extrudates. The density of the original billet was $0.902_{5} \mathrm{~g} \mathrm{~cm}^{-3}$, from which the degree of crystallinity was estimated to be $51.0 \%$. At first, the density increased with degradation time and then leveled off to about $0.950 \mathrm{~g} \mathrm{~cm}^{-3}$ after $30 \mathrm{~h}$. The original densities of the two extrudates were each $0.913_{0} \mathrm{~g} \mathrm{~cm}^{-3}$, corresponding to a crystallinity of $66.7 \%$. The densities increased gradually with degradation time up to about $30 \mathrm{~h}$ and then leveled off to about $0.943_{0} \mathrm{~g} \mathrm{~cm}^{-3}$. It should be noted that both extrudates had the same density throughout the entire period of degradation exam-

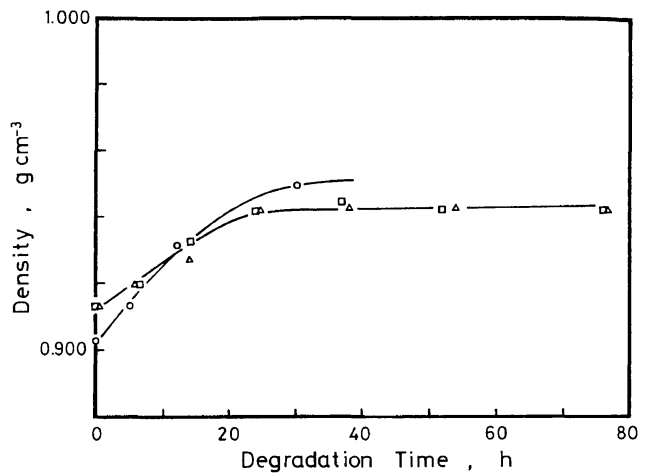

Figure 6. Dependence of density on degradation time for the original billet $(O)$ and the two products with $R_{\mathrm{e}}=5.2(\triangle)$ and $6.5(\square)$.

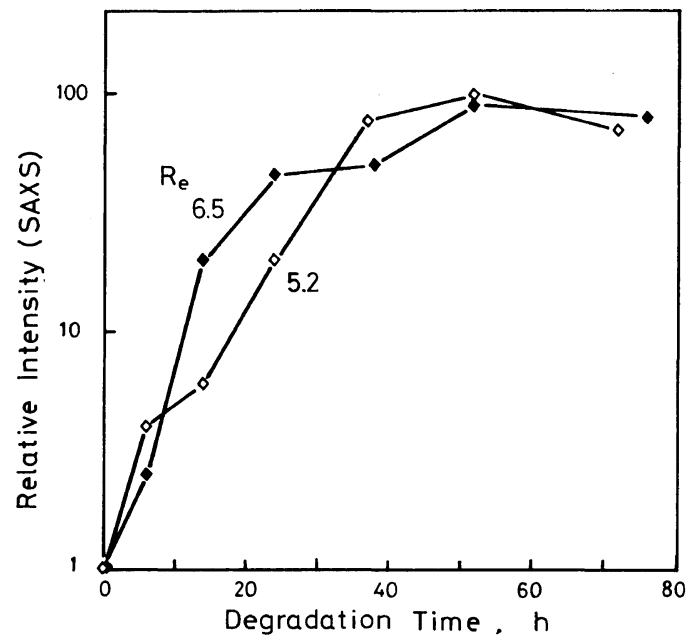

Figure 7. Dependence of SAXS peak intensity on degradation time for the two products with $R_{\mathrm{e}} 5.2$ and 6.5 .

ined. This suggests that both extrudates have the same fine structure, although axial long periods were quite different.

Figure 7 shows the degradation time dependence of SAXS intensity for the two extrudates with $R_{\mathrm{e}}=$ 5.2 and 6.5. It is evident that the intensities of the meridional maxima of the SAXS patterns increase steeply with degradation time and then level off after about $30-40 \mathrm{~h}$. The axial long periods were almost constant during the degradation period. This behavior corresponds well to the degradation time dependence of density shown above, and suggests strongly that the molecular chains in the amorphous 
region between crystallites become progressively broken while, at the same time, the density of the amorphous region undergoes a steady decrease. Accordingly, it may be concluded that the contrast in the SAXS intensities of the crystalline and amorphous regions becomes more pronounced as degradation proceeds.

\section{Gel-Permeation Chromatography}

Figure 8 shows the GPC curves of the original billet degraded with fuming nitric acid for indicated periods of time. This figure also shows double peaks with a $2: 1$ molecular weight ratio for times exceeding about $10 \mathrm{~h}$. Such double peaks are normally observed in degradation experiments on polyethylene folded-chain crystals, which resemble solution-grown single crystals and bulk-crystallized samples. The height of the higher molecular weight peak decreased as the folded-chains were cut.

Figures 9 and 10 show the GPC curves of the extrudates with $R_{\mathrm{e}}=5.2$ and 6.5 respectively which were degraded for specified periods of time. The curves in Figure 10 show only one peak for any

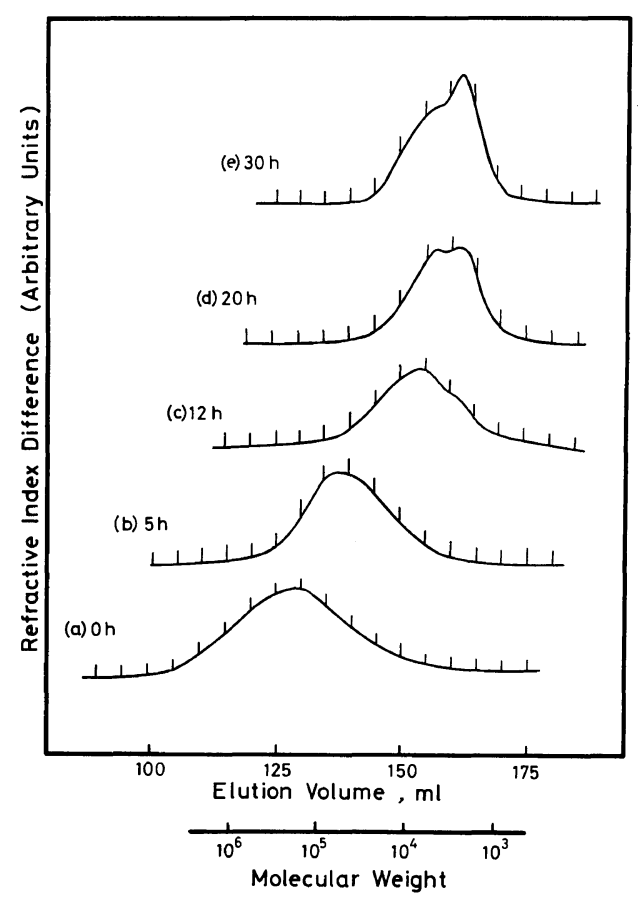

Figure 8. Change in GPC curves of the original billet degraded with fuming nitric acid for the time periods indicated. degradation time; such a peak grows sharply for time periods exceeding about $24 \mathrm{~h}$. Further etching of the sample results in a slight dimution of the peak breadth. The presence of a single, narrow peak corresponding to a single traverse in the crystal lamellae is in accord with other studies on oriented polyethylene. ${ }^{15-17}$ The GPC curves in Figure 9 are almost the same as those in Figure 10, except for the slight existence of a double chain traverse peak recorded at $14 \mathrm{~h}$ and $24 \mathrm{~h}$. It is noteworthy that these GPC curves indicate different effects of etching on the original billet and the extrudate with $R_{\mathrm{e}}=6.5$. Figure 10 suggests that the PP extrudate with $R_{\mathrm{e}}=6.5$ prepared at $150^{\circ} \mathrm{C}$ has limited chain folding.

Figure 11 shows the chain length of the GPC lowest molecular weight peak as a function of degradation time for the billet and the two extrudates. In all cases, a rapid initial reduction of the

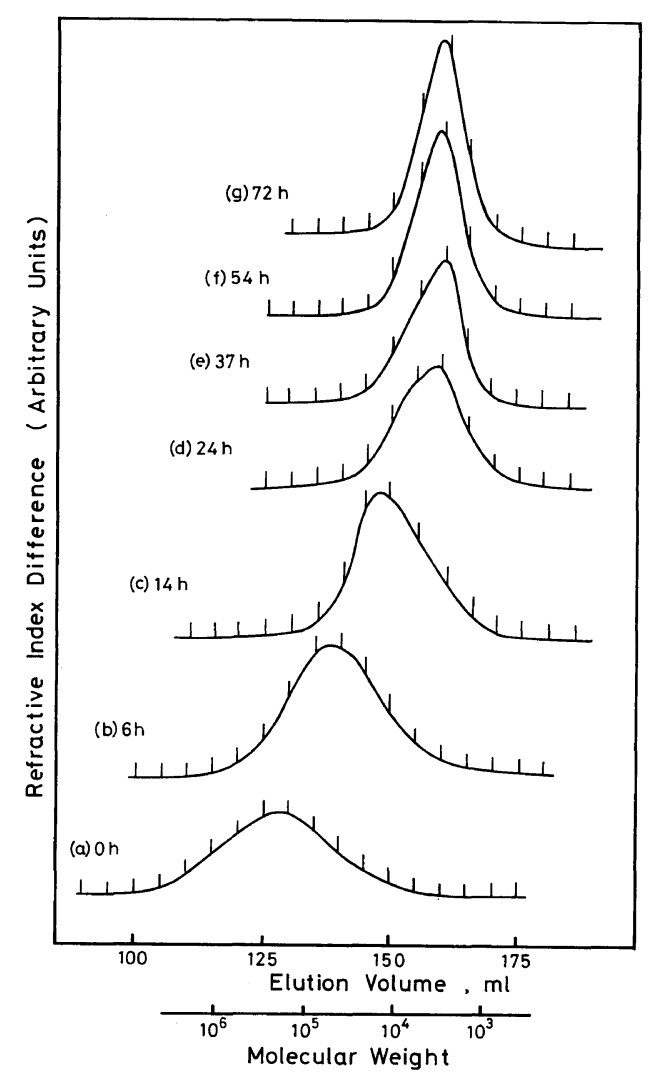

Figure 9. Change in GPC curves of the extrudate for $R_{\mathrm{e}}=5.2$ degraded with fuming nitric acid for the time periods indicated. 
peak chain length followed by leveling off at about $20 \mathrm{~h}$ could be observed. All samples showed a decrease in the rate of chain length reduction at longer times. The reason for this may be that the surfaces of the crystals are covered with degradation products and the activity of degradation decreases for more than a certain period of time. However, at the same time, it may be said that when a PP resin is

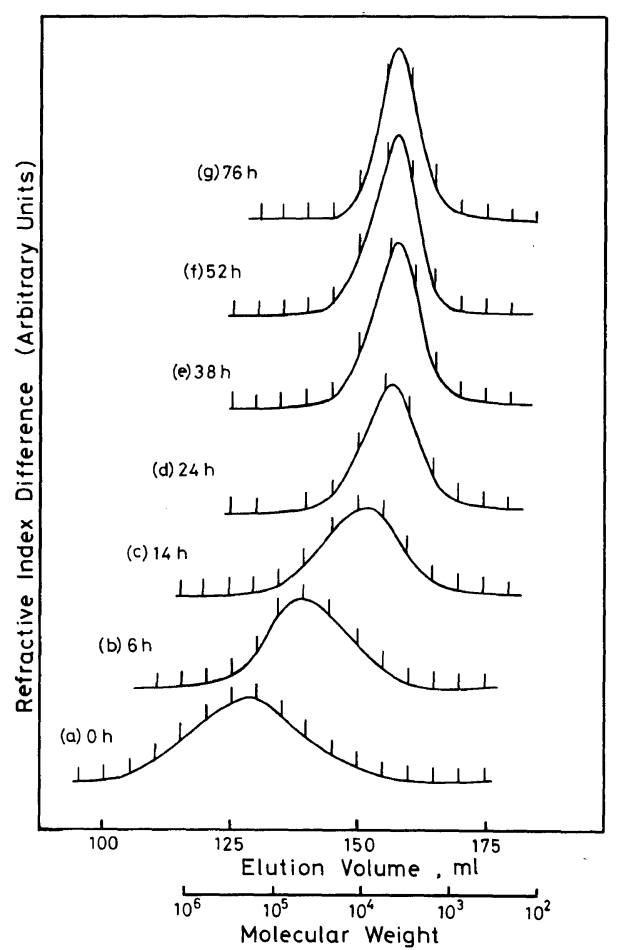

Figure 10. Change in GPC curves of the extrudate for $R_{\mathrm{e}}=6.5$ degraded with fuming nitric acid for the time periods indicated. etched for more than about $30 \mathrm{~h}$, almost all the chain molecules in the amorphous region between crystallites are broken up completely. Accordingly, it seems reasonable to conclude that the GPC patterns at longer times correspond approximately to the lamellar thickness distributions of crystallites in the samples and that the GPC lowest molecular weight peak is converted to single chain traverse length. Moreover, the GPC peak chain length may correspond to the average thickness of crystallite cores in the degraded samples, since the GPC curves recorded at long degradation times became approximately symmetrical. An approximate average lamellar thickness of the original crystals in each sample was determined by extrapolating a linear relation between peak chain length and time to zero

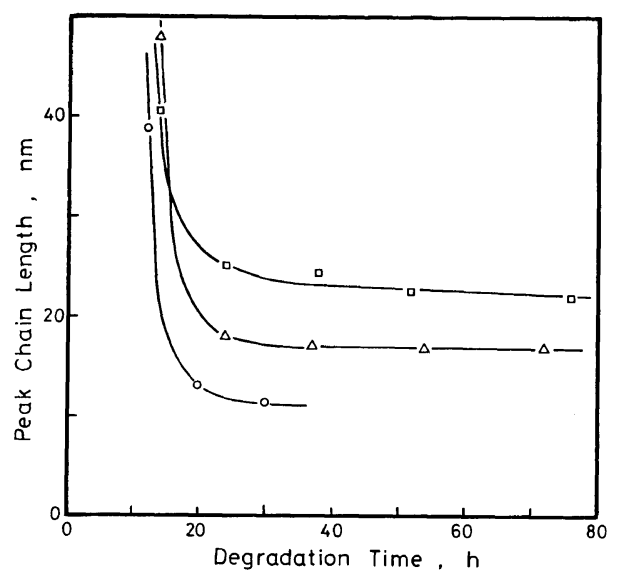

Figure 11. Dependence of GPC peak chain length on degradation time for the original billet $(O)$ and the two extrudates prepared at $150^{\circ} \mathrm{C}$ with $R_{\mathrm{e}}=5.2(\triangle)$ and 6.5 (口).

Table 1. Dependence of crystal size distribution on degradation time $\left(t_{\mathrm{d}}\right)$ for the two PP products extruded hydrostatically at $150^{\circ} \mathrm{C}$ with extrusion ratios of $R_{\mathrm{e}}=5.2$ and $R_{\mathrm{e}}=6.5$

\begin{tabular}{|c|c|c|c|c|c|c|}
\hline \multirow{2}{*}{$R_{\mathrm{e}}$} & $t_{\mathrm{d}}$ & \multirow{2}{*}{$M_{n}$} & \multirow{2}{*}{$M_{w}$} & $M_{w}$ & $L_{n}$ & $L_{w}$ \\
\hline & $\mathrm{h}$ & & & $M_{n}$ & $\mathrm{~nm}$ & $\mathrm{~nm}$ \\
\hline \multirow[t]{3}{*}{5.2} & 37 & 3350 & 5600 & $1.6_{7}$ & 17.2 & 28.9 \\
\hline & 54 & 2900 & 4400 & $1.5_{2}$ & 15.0 & 22.7 \\
\hline & 72 & 2700 & 4000 & $1.4_{8}$ & 13.9 & 20.6 \\
\hline \multirow[t]{2}{*}{6.5} & 38 & 3500 & 5500 & $1.5_{7}$ & 18.1 & 28.4 \\
\hline & 76 & 3500 & 4800 & $1.3_{5}$ & 18.1 & 24.8 \\
\hline
\end{tabular}


Table II. Data for layer thickness of polypropylene hydrostatically extruded at $150^{\circ} \mathrm{C}$

\begin{tabular}{|c|c|c|c|}
\hline Sample & $\begin{array}{l}\text { Long period, } \\
\qquad L\end{array}$ & $\begin{array}{c}\text { GPC peak chain length } \\
\text { (crystalline thickness), } \\
L_{\mathrm{c}}\end{array}$ & $\begin{array}{l}\text { Amorphous thickness, } \\
\qquad L_{\mathrm{a}}\end{array}$ \\
\hline & $\mathrm{nm}$ & $\mathrm{nm}$ & $\mathrm{nm}$ \\
\hline $\begin{array}{l}\text { Original billet } \\
\text { Extrudates }\end{array}$ & 14.9 & $11.5 \pm 1.0$ & $3.4 \pm 1.0$ \\
\hline$R_{\mathrm{e}}=5.2$ & 22.1 & $17.5 \pm 1.0$ & $4.6 \pm 1.0$ \\
\hline$R_{\mathrm{e}}=6.5$ & 30.4 & $24.0 \pm 1.0$ & $6.4 \pm 1.0$ \\
\hline
\end{tabular}

time as $11.5 \pm 1.0 \mathrm{~nm}$ for the billet, $17.5 \pm 1.0 \mathrm{~nm}$ for the product with $R_{\mathrm{e}}=5.2$, and $24.0 \pm 1.0 \mathrm{~nm}$ for the product with $R_{\mathrm{e}}=6.5$.

A quantitative measure of molecular weight distribution is given by number- and weight-average molecular weights derived from the GPC curves in Figures 9 and 10. The results are presented in Table I. The main peaks for both extrudates had fairly narrow spreads at times exceeding $30 \mathrm{~h}$. The product with $R_{\mathrm{e}}=6.5$ had a narrower molecular weight distribution than that of the product with $R_{\mathrm{e}}=5.2$. These results indicate that the product with $R_{\mathrm{e}}=6.5$ had a larger average crystal thickness and a narrower lamellar thickness distribution than the product with $R_{\mathrm{e}}=5.2$.

Table II illustrates the data of X-ray long period and GPC peak chain length for the original billet and the two extrudates. It can be seen that the peak chain lengths corresponding to the average lamellar thicknesses for the extrudates increase with extrusion ratio. This behavior is consistant with the fact that the "equilibrium" melting temperature of the product with $R_{\mathrm{e}}=6.5$ is higher than that of the product with $R_{\mathrm{e}}=5.2$. The discrepancy between $\mathrm{X}$ ray long period and GPC peak chain length may be ascribed approximately to the layer thickness of the amorphous region between crystallites in the extrudates. Both the crystalline and amorphous layers in the extrudate with $R_{\mathrm{e}}=6.5$ increased remarkably during extrusion. But the ratios of amorphous to crystalline layer thicknesses for the two extrudates with $R_{\mathrm{e}}=5.2$ and 6.5 were almost equal to 0.27 , while this ratio for the original billet was about 0.29 .

\section{DISCUSSION}

Plastic deformation of fibrous materials such as fibers and highly drawn films can be explained by Peterlin's model ${ }^{18}$ of microfibrillar morphology. In particular, this model is useful for the bundling of microfibrils into long, densely packed fibrils. It is already known from wide-angle $\mathrm{X}$-ray scattering, SAXS, and birefringence studies ${ }^{6}$ that hydrostatic extrusion of isotactic PP at high extrusion ratios changes the morphological structure from microspherulitic crystalline lamellae to highly oriented fiber structure by a deformation process such as the rotation and sliding of lamellar crystals and the rearrangement of microfibrils and that the chain axis of microcrystals in the microfibrils becomes oriented in the extrusion direction. This information allows application of the two-phase model to PP extrudates displaying two-intensity meridional SAXS diagrams. It is very interesting to estimate the effect of extrusion ratio on the layer thicknesses of crystalline and amorphous regions in the PP extrudates with different axial long periods.

The unusual increase in the $\mathrm{X}$-ray long period and GPC peak chain length, i.e., average crystal thickness, was observed at the highest extrusion ratio for the extrudates prepared at 130 and $150^{\circ} \mathrm{C}$. Two possibilities may be considered in the extrusion of isotactic PP. First, annealing after extrusion may contribute to the thickening of lamellar structure, giving it more stability since a sample cannot be cooled rapidly enough. The thickening mechanism may be either solid-state annealing at lower temperature or partial melting and recrystallization process at higher temperature. However, these contributions are considered to be of slight significance.

Second, the adiabatic heating effect on a die during extrusion may be considered to be fairly large. The existence of an adiabatic thermal regime in hydrostatic extrusion has been discussed by 
Alexander and Wormell ${ }^{19}$ for low density polyethylene and poly(vinyl chloride), and by Gibson and Ward ${ }^{20}$ for linear polyethylene. These authors suggest that the work dissipated in the extrusion process may cause a substantial rise in the temperature of the product, especially for high-speed extrusions of large-diameter material. It is known that observed instabilities such as "stick-slip" phenomenon are invariably accompanied by severe product distortion. These are almost certainly due to the process of "hunting" between stable isothermal and adiabatic states. Since extrusion at $R_{\mathrm{e}}=6.5$ was the highest limit for obtaining smooth PP product, heat was probably generated locally in the die region as a result of mechanical deformation during extrusion. When this occurs, the sample temperature became higher than the extrusion predetermined temperature.

In crystallization kinetics, the lamellar thickness of crystals is determined by the degree of undercooling. The variables for undercooling in the extrusion experiments are actual pressure and actual temperature in the sample during deformation, but these cannot be determined correctly. At small extrusion rates, actual pressure may be approximately substituted by extrusion pressure. On the other hand, the actual temperature of a sample in the die region should be more or less higher than the extrusion temperature predetermined. Application of hydrostatic pressure on a polymer sample allows its melting temperature to increase and contributes to increasing the degree of undercooling, while high temperature and additional heat of deformation

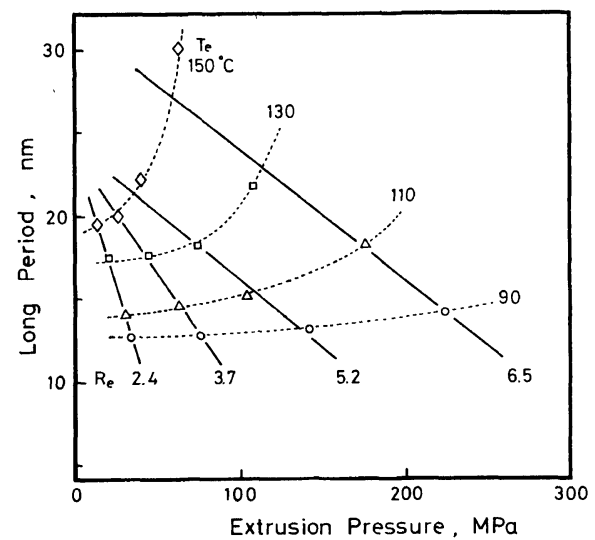

Figure 12. Relation of X-ray long period to extrusion pressure for the PP extrudates. give rise to decrease in the extent of undercooling. Accordingly, the dependence of X-ray long period on extrusion ratio may be understood qualitatively in terms of undercooling. The data in Figure 5 are replotted in Figure 12 as a function of extrusion pressure. Linear relations between the X-ray long period and extrusion pressure can be seen for all the PP extrudates. The long periods for extrudates with $R_{\mathrm{e}}=2.4,3.7$, and 5.2 approximately converge to about $24 \mathrm{~nm}$ at zero extrusion pressure, while that for the extrudate with $R_{\mathrm{e}}=6.5$ was extrapolated to about $32 \mathrm{~nm}$. There occurs only a slight increase in the long period at $90^{\circ} \mathrm{C}$, since the temperature is much lower than the melting point and higher pressure is necessary for extrusion at a high ratio. In this situation, undercooling becomes to a considerable degree and the possible contribution by deformational heat is negligible and then the lamellar thickness can be determined by the mechanical deformation processes. On the other hand, there occurs a large increase in the long period for the extrudates prepared at 130 and $150^{\circ} \mathrm{C}$ with $R_{\mathrm{e}}=6.5$ because extrusion can be performed at lower extrusion pressure and higher temperature under which conditions the degree of undercooling is lowered. Moreover, additional heat of deformation will contribute to lessening the degree of undercooling. In such a case, an appreciable lamellar thickening is considered to occur with the mechanical deformation of crystallites and amorphous chains during extrusion. However, at the same time, the amorphous orientation both in the inter- and intramicrofibrils of the extrudates is disturbed at small undercoolings.

Taking into account the extrusion of isotactic PP at high extrusion ratios, it is plausible that the spherulitic structure with relatively low crystallinity undergoes mechanical deformations such as rotation, sliding, and orientation of microcrystals in the extrusion direction, accompanied by a thickening of both the lamellar core and amorphous layer between the crystallites in the microfibrils. This suggests that portion of the polymer molecules in the amorphous region of the original billet is considered to move into the crystalline and amorphous regions of the microfibrils, and the remaining amorphous portion being oriented between the microfibrils during hydrostatic extrusion and that on the whole the polymer molecules in the extrudates are well aligned to the extrusion 
direction.

\section{REFERENCES}

1. T. Williams, J. Mater. Sci., 8, 59 (1973).

2. H. N. Yoon, K. D. Pae, and J. A. Sauer, Polym. Eng. Sci., 16, 567 (1976).

3. K. Nakamura, K. Imada, and M. Takayanagi, Polymer, 15, 446 (1974).

4. K. Nakayama and H. Kanetsuna, J. Mater. Sci., 10, 1105 (1975); ibid., 12, 1477 (1977).

5. K. Nakayama and H. Kanetsuna, J. Jpn. Soc. Technol. Plast., 20, 229 (1979).

6. K. Nakayama, H. Kanetsuna, and E. Noda, J. Jpn. Soc. Technol. Plast., 20, 820 (1979).

7. K. Nakayama and H. Kanetsuna, Kobunshi Ronbunshu, 35, 419 (1978).

8. K. Nakayama, K. Satake, T. Oki, and H. Kanetsuna, J. Jpn. Soc. Technol. Plast., 15, 744 (1974).

9. K. Nakayama, K. Watanabe, T. Kobayashi, and H.
Kanetsuna, Polym. Prepr., Jpn., 27, 614 (1978).

10. G. Farrow, Polymer, 2, 409 (1960).

11. Y. Maeda and H. Kanetsuna, Polym. J., 13, 357 (1981).

12. F. C. Frank, I. M. Ward, and T. Williams, J. Polym. Sci., A-2, 6, 1357 (1968).

13. T. Williams, Y. Udagawa, A. Keller, and I. M. Ward, J. Polym. Sci., A-2, 8, 35 (1970).

14. C. H. Hock, J. Polym. Sci., A-2, 4, 227 (1966).

15. I. M. Ward and T. Williams, J. Macromol. Sci., Phys., B5, 693 (1971).

16. N. E. Weeks, S. Mori, and R. S. Porter, J. Polym. Sci., Polym. Phys. Ed., 13, 2031 (19.75).

17. G. Capaccio and I. M. Ward, J. Polym. Sci., Polym. Phys. Ed., 19, 667 (1981).

18. A. Peterlin, Colloid Polym. Sci., 253, 809 (1975).

19. J. M. Alexander and P. J. Wormell, Ann. CIRP, 19, 21 (1971).

20. A. C. Gibson and I. M. Ward, J. Polym. Sci., Polym. Phys. Ed., 16, 2031 (1978). 